\title{
CATASTROPHIC PAYMENTS FOR HEALTH CARE IN ASIA
}

\author{
EDDY VAN DOORSLAER ${ }^{\mathrm{a}, *}$, OWEN O'DONNELL $^{\mathrm{b}}$, RAVINDRA P. RANNAN-ELIYA $^{\mathrm{c}}$, APARNAA $^{-}$ \\ SOMANATHAN ${ }^{\mathrm{c}}$, SHIVA RAJ ADHIKARI ${ }^{\mathrm{d}}$, CHARU C. GARG ${ }^{\mathrm{e}}$, DENI HARBIANTO ${ }^{\mathrm{f}}$, ALEJANDRO N. \\ HERRIN $^{\mathrm{g}}$, MOHAMMED NAZMUL HUQ ${ }^{\mathrm{h}}$, SHAMSIA IBRAGIMOVA ${ }^{\mathrm{i}}$, ANUP KARAN ${ }^{\mathrm{j}}$, TAE-JIN LEE ${ }^{\mathrm{k}}$, \\ GABRIEL M. LEUNG ${ }^{1}$, JUI-FEN RACHEL LU ${ }^{\mathrm{m}}$, CHIU WAN NG ${ }^{\mathrm{n}}$, BADRI RAJ PANDE ${ }^{\mathrm{d}}$, RACHEL \\ RACELIS $^{\mathrm{g}}$, SIHAI TAO ${ }^{\circ}$, KEITH TIN $^{1}$, KANJANA TISAYATICOM $^{\mathrm{p}}$, LAKSONO TRISNANTORO $^{\mathrm{f}}$, \\ CHITPRANEE VASAVID ${ }^{\mathrm{p}}$ and YUXIN ZHAO ${ }^{\mathrm{q}}$

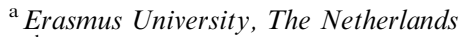 \\ ${ }^{\mathrm{b}}$ University of Macedonia, Greece \\ ${ }^{\mathrm{c}}$ Institute for Health Policy, Sri Lanka \\ ${ }^{\mathrm{d}}$ Nepal Health Economics Association, Nepal \\ ${ }^{\mathrm{e}}$ World Health Organisation, Switzerland \\ ${ }^{\mathrm{f}}$ Gadjah Mada University, Indonesia \\ ${ }^{\mathrm{g}}$ University of the Philippines, Philippines \\ ${ }^{\mathrm{h}}$ Jahangirnagar University, Bangladesh \\ ${ }^{\mathrm{i}}$ National Statistical Committee, Kyrgyz Republic \\ ${ }^{\mathrm{j}}$ Institute for Human Development, India \\ ${ }^{\mathrm{k}}$ Hallym University, South Korea \\ ${ }^{1}$ University of Hong Kong, Hong Kong SAR \\ ${ }^{\mathrm{m}}$ Chang Gung University, Taiwan \\ ${ }^{\mathrm{n}}$ University of Malaysia, Malaysia \\ ${ }^{\circ}$ North China Coal Medical College, China \\ ${ }^{\mathrm{p}}$ International Health Policy Program, Thailand \\ ${ }^{\mathrm{q}}$ National Health Economics Institute, China
}

\begin{abstract}
SUMMARY
Out-of-pocket (OOP) payments are the principal means of financing health care throughout much of Asia. We estimate the magnitude and distribution of OOP payments for health care in fourteen countries and territories accounting for $81 \%$ of the Asian population. We focus on payments that are catastrophic, in the sense of severely disrupting household living standards, and approximate such payments by those absorbing a large fraction of household resources. Bangladesh, China, India, Nepal and Vietnam rely most heavily on OOP financing and have the highest incidence of catastrophic payments. Sri Lanka, Thailand and Malaysia stand out as low to middle income countries that have constrained both the OOP share of health financing and the catastrophic impact of direct payments. In most low/middle-income countries, the better-off are more likely to spend a large fraction of total household resources on health care. This may reflect the inability of the poorest of the poor to divert resources from other basic needs and possibly the protection of the poor from user charges offered in some countries. But in China, Kyrgyz and Vietnam, where there are no exemptions of the poor from charges, they are as, or even more, likely to incur catastrophic payments. Copyright (C) 2007 John Wiley \& Sons, Ltd.
\end{abstract}

Received 1 August 2005; Revised 17 November 2006; Accepted 6 December 2006

KEY WORDS: health care financing; catastrophic health payments; Asia

\section{INTRODUCTION}

Out-of-pocket payments are the principal means of financing health care throughout much of Asia (O'Donnell et al., 2005). This has consequences for the utilisation of health care and subsequently

\footnotetext{
*Correspondence to: Department of Health Policy and Management, Erasmus University, Rotterdam, The Netherlands. E-mail: vandoorslaer@few.eur.nl
} 
health. There are also potentially important consequences for household living standards. Welfare is reduced by the uncertainty of medical expenditures. Households may be able to borrow to cover unexpected medical bills but at the risk of being trapped in long-term debt. As a result, opportunities to escape poverty through investments in human capital may be lost. Where there is a lack of access to credit, a characteristic of less-developed economies particularly binding for the financing of investments in health, medical expenses must be covered from the current household budget and from wealth. Some households might be able to finance medical expenses from savings, by selling assets or by cutting back on expendable items of consumption. More severely economically constrained households may be forced to cut back on necessities and consequently be pushed into poverty. Illness then presents a difficult choice between diverting a large fraction of household resources to cover the costs of treatment and forgoing treatment at the expense of health.

The threat that out-of-pocket (OOP) payments pose to household living standards is increasingly recognised as a major consideration in the financing of health care (Commission on Macroeconomics and Health, 2001; OECD and WHO, 2003; World Bank, 2004; World Health Organisation, 2005). The extent to which such concern is justified depends upon the unpredictability of OOP payments, their magnitude relative to household resources and their distribution in relation to that of income. We describe the magnitude and distribution of OOP payments for health care in fourteen countries and territories that account for $81 \%$ of the total population of Asia (49\% of the world population). Our focus is on expenditures that are catastrophic, in the sense that they severely disrupt household living standards. Following others (Berki, 1986; Wyszewianski, 1986; Wagstaff and Van Doorslaer, 2003; $\mathrm{Xu}$ et al., 2003; Russell, 2004), we approximate such catastrophic payments by those in excess of a substantial fraction of the household budget. Spending a large fraction of household resources on health care can threaten living standards either in the short term, as current consumption of other goods and services must be sacrificed, or in the long term, as assets are divested, savings depleted or debt accumulated. One conception of fairness in health finance is that households should be protected against such catastrophic medical expenses (World Health Organisation, 2000).

Most previous estimates of the impact of OOP payments on living standards in developing countries have relied on data from small-scale health surveys that are not nationally representative, often being restricted to rural areas (Sauerbron et al., 1995; Ensor and Pham, 1996; Sauerbron et al., 1996; Pannarunothai and Mills, 1997; Wilkes et al., 1998; Fabricant et al., 1999; Ranson, 2002; Segall et al., 2002; Skarbinski et al., 2002; Russell, 2004; van Damme, 2004). We analyse data from nationally representative household expenditure surveys that record both OOP payments for health care and total household expenditure in detail and so offer accurate estimates of the magnitude of OOP payments relative to the household budget. We extend the existing evidence on catastrophic payments derived from nationally representative expenditure data (Pradhan and Prescott, 2002; Wagstaff and Van Doorslaer, 2003; Xu et al., 2003) by adding estimates for China and India, and many other Asian countries.

The structure of the paper is as follows. Next, we provide background information on the financing contribution and composition of OOP payments and on public health care charging policy in each of the fourteen study territories. Then we summarise the magnitude and distribution of OOP payments relative to household budgets. Further, the extent to which OOP payments for health care are catastrophic is examined. Finally, we summarise and interpret the main findings, and acknowledge some limitations.

\section{OUT-OF-POCKET FINANCING OF HEALTH CARE IN ASIA}

The fourteen territories included in the analysis span the whole range of economic development from low to high income (Table I). In each case, OOP payments fund at least $30 \%$, and often much more, of 





total expenditure on health (Table I). Poorer countries rely more heavily on direct payments. The OOP contribution reaches three-quarters or more of total expenditure on health (THE) in Nepal, India and Vietnam. OOP financing has been reduced in Hong Kong, Malaysia and Thailand by greater reliance on taxation and in Taiwan and South Korea through the development of universal social insurance. In Korea, heavy use of co-payments means that one half of TEH is still financed directly out-of-pocket.

Our analysis is based on OOP payments reported in household expenditure or socio-economic surveys. Details of the surveys are given in Table AI of Appendix A. OOP payments include fees, insurance co-payments, user charges for public care and purchases of medicines, appliances, diagnostic tests, etc (see Table III). Expenditures on both Western and traditional care are included. The shares of total OOP payments that are for public sector care and the percentages of the total on inpatient, ambulatory, medicines and other types of care are given in Table I. In some cases it is not possible to make this disaggregation since the survey asks only for total OOP payments for health care.

In Bangladesh and Sri Lanka, only a tiny fraction of OOP payments are for care delivered in the public sector. In Sri Lanka, care in the public sector is free, with the rather peculiar exception of family planning (Table II). In Bangladesh, most primary care is free and there is only a nominal registration charge for inpatient and outpatient care in secondary facilities. There are charges for inpatient care at major public hospitals but the poor and civil servants are exempt (Table II). In principle, medicines are free within facilities but in practice most medicines must be purchased from drug outlets. This, in addition to the widespread use of unqualified providers of modern and traditional medicine, accounts for the low share of total OOP payments that is for public sector care in Bangladesh (Data International Ltd., 2004). Public sector charges constitute a very modest share of total OOP payments in Hong Kong, where charges are made for inpatient and outpatient care but at a very moderate level and with exemptions for the poor, civil servants and health service staff (Table II). Malaysia is similar but with less exemptions for the poor. By contrast, payments for care received in the public sector account for around a quarter of total OOP payments in India and Indonesia and more than a third in Thailand and Vietnam and more than two-fifths in Kyrgyz (Table I). ${ }^{1}$ There are user charges for virtually all public sector medical care and medicines in Indonesia. This is also the case in Thailand but since the 2001 universal coverage reform there has been a flat charge equivalent to around 70 US cents per day. Charges are levied for all public sector care in Vietnam, with the exception of outpatient care at health centres (Table II). In India, primary care delivered at some or all facilities is free, at least in principle. The same is true in Kyrgyz and the Philippines and there is a $60 \%$ subsidy for care at health posts and primary care centres in Nepal. There are no charges for vaccinations, immunisations and family planning services in Bangladesh, China, India, Malaysia, Nepal, Taiwan and Thailand. Consultations with hospital specialists are free only in India and Kyrgyz.

Exemptions of the poor from public sector user charges and co-payments in Bangladesh, Hong Kong, Indonesia, Malaysia, Nepal, the Philippines, Taiwan, Thailand and Vietnam may reduce the impoverishing effect of such charges. But this depends upon the implementation of fee waivers. There are known problems with implementation in Bangladesh, Nepal, and the Philippines, often because shortage of medicines means that they must be paid for. In Indonesia and Thailand, charges are levied on most medical services but effective health card systems help to shield the poor (Khoman, 1997; Saadah et al., 2001). In India, subsidisation of the poor works indirectly, through price discrimination. The poor can opt for lower quality but cheaper inpatient care on separate wards. This arrangement also operates in Indonesia. Informally, the poor or those considered unable to pay are likely to be exempted from charges in parts of India, Sri Lanka and Thailand. Kyrgyz and Thailand exempt both children and the elderly from charges. The elderly are exempt in the Philippines and pay a reduced co-payment in Korea.

\footnotetext{
${ }^{1}$ Payments for medicines prescribed at public sector facilities are included.
} 


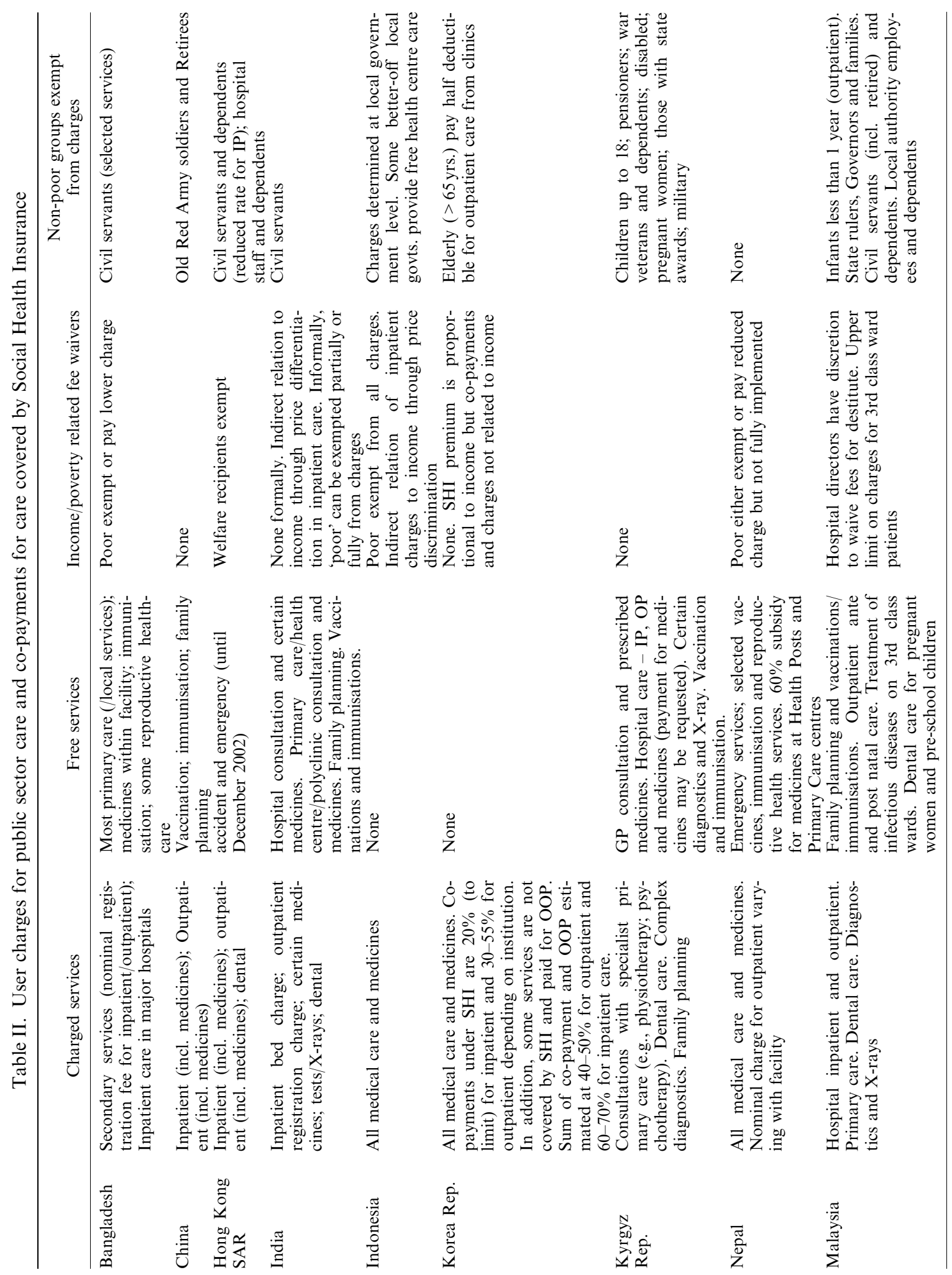




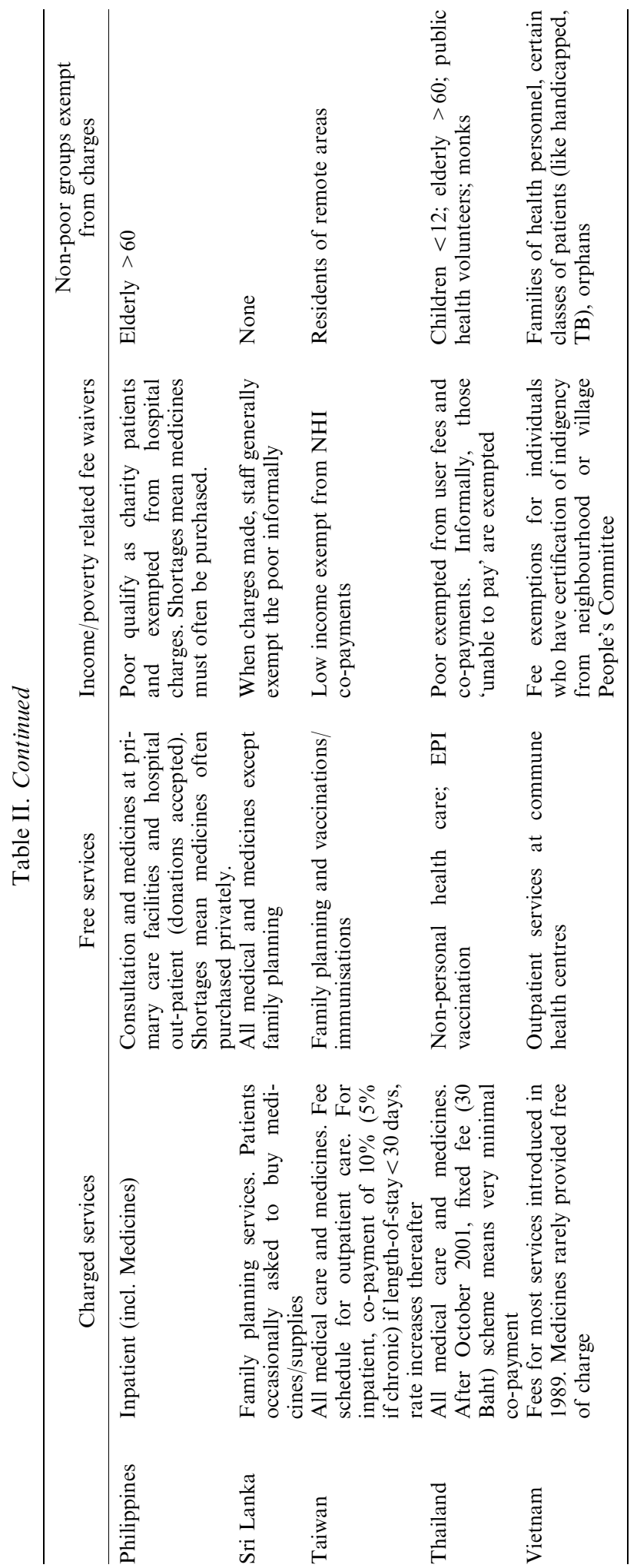


Comparing shares of OOP payments for inpatient care, ambulatory care and medicines is difficult given differences across surveys in the categorisation of expenditures. For this reason, we do not attempt to compare catastrophic payments due to different categories of expenditure. Nonetheless, the estimates presented in Table I reveal some consistencies in the composition of OOP payments that deserve comment. There are also some cross-country differences that do not seem spurious but reflections of differences in environment and policy. In general, inpatient care does not absorb the largest share of OOP payments. More is spent out-of-pocket on ambulatory care and on medicines. If this were not the case, the catastrophic impact of OOP payments would be greater since they would be concentrated on a fewer number of households receiving inpatient care. South Korea is the one exception, where $40 \%$ of OOP payments are for inpatient care. This is to be expected given that social insurance covers only $30-40 \%$ of the costs of inpatient care (Table II). In contrast, there is $90-95 \%$ coverage of inpatient costs in Taiwan and, as a result, only $10 \%$ of OOP payments are for inpatient care.

The share of total OOP payments that goes on medicines is generally larger in the poorer, more rural countries. The share is $70 \%$ or more in Bangladesh, India and Vietnam. This is consistent with the greater prevalence of self-medication in poorer and particularly rural societies in which access to health services is constrained by income and distance (Chang and Trivedi, 2003). Self-medication, which often has little or no positive effect on health, is a recognised problem in South Asia (Mudur, 1999). Arguably, absorption of constrained household budgets by payments for medication is even more catastrophic when there is so little return in terms of health. But the entire OOP share attributed to medicines is not due to self-treatment. It includes medicines prescribed during treatment but purchased by the patient separately. In Bangladesh and Vietnam, the OOP shares on medicines are 70 and $88 \%$, respectively, when all expenditures on medicines are included - those prescribed during treatment and not. When payments for prescribed medicines are included with the respective inpatient and ambulatory expenditures, the share of OOP spent on medicines, which is due to self-medication, is only $6.3 \%$ in Bangladesh and $37 \%$ in Vietnam. Nonetheless, spending on drugs, prescribed or not, generally accounts for a very large fraction of OOP payments. Drug pricing and charging policy, but also utilisation practices, deserve particular consideration in formulating policies to limit the impact of health care payments on household welfare.

\section{HOUSEHOLD BUDGET SHARES OF OUT-OF-POCKET PAYMENTS}

The incidence of catastrophic payments, defined as payments in excess of a threshold budget share, depends upon the location and dispersion of the distribution of OOP payments relative to household resources. Before presenting measures of catastrophic payments, we examine the OOP budget shares distributions. For low- and middle-income countries, the household budget is defined as the value of consumption, including that from home production (see Table III). For the high-income territories (Hong Kong, Taiwan and South Korea), the household budget is given by expenditure on market goods and services. Each survey contains detailed data on OOP payments for health care, covering at least payments for inpatient care, outpatient care and medicines (Table III). These data are potentially subject to both recall bias and small sample bias due to the infrequency with which some health care payments are made. Longer recall periods should reduce bias through infrequency of purchase but at the cost of increasing recall bias. Survey estimates of aggregate health care payments tend to show discrepancies from production-side estimates, where the latter are available. There also tend to be discrepancies, at times substantial, between estimates of total private expenditure obtained from surveys and from national accounts procedures (Deaton, 2004). In the present context, there is a problem if measurement error in OOP payments for health care differs substantially from that in other items of expenditure. It is very difficult to verify whether this is the case and there is little option but to rely on the expenditure survey estimates of the OOP budget share. 


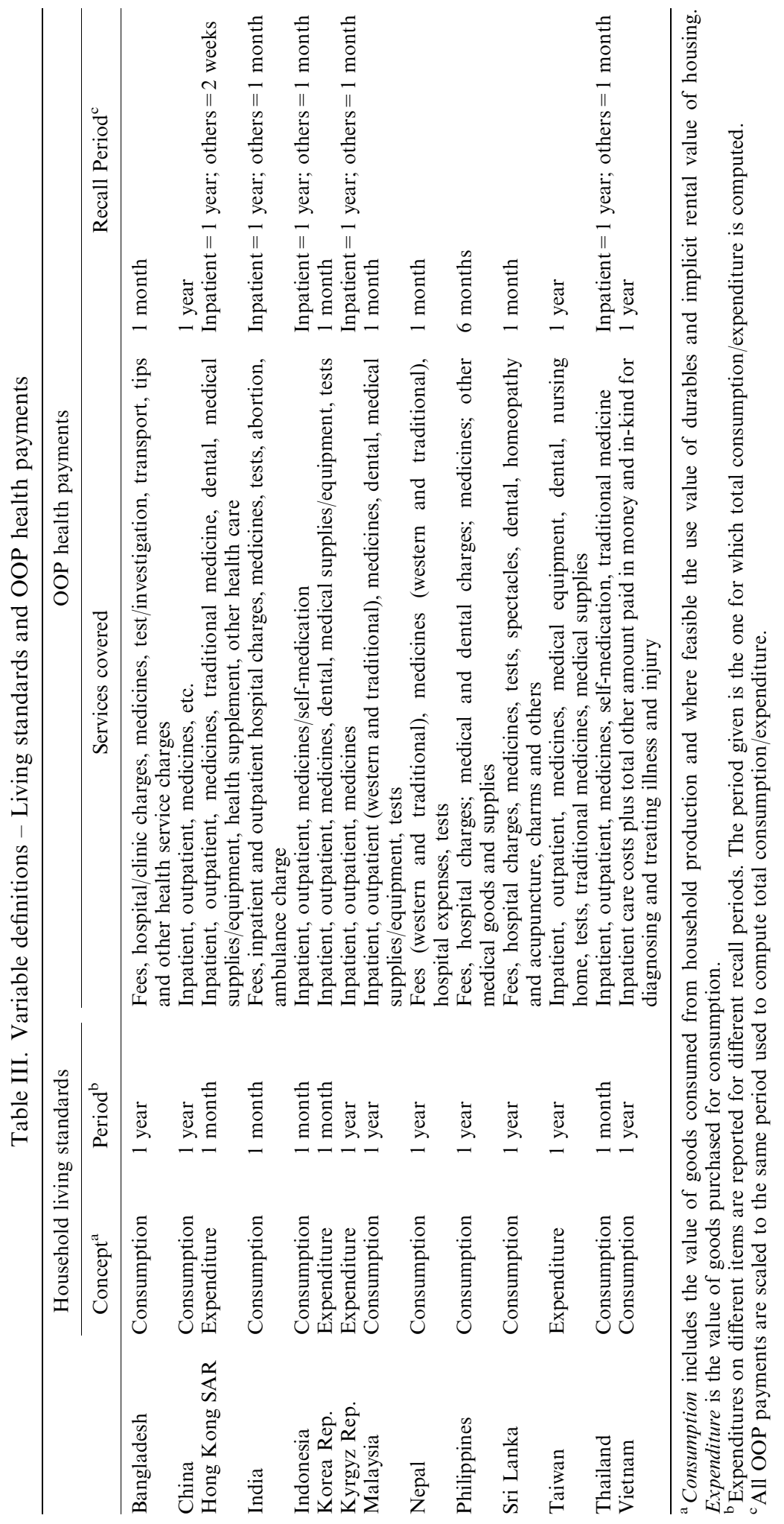


There is substantial variation across territories in the mean OOP budget share (Table IV). Averaged across all households, OOP payments for health care absorb $4-5.5 \%$ of total household consumption in China, India, Bangladesh and Vietnam. All four of these countries rely on OOP payments for at least $60 \%$ of health financing. With the exception of (urban) China, they are among the poorest countries examined here. Associated with poverty, population health deficiencies drive up expenditures on health care and medicines. The mean OOP budget share is much lower - 1.4-2.7\% - in Malaysia, Thailand, Indonesia, the Philippines, Sri Lanka, Hong Kong, Kyrgyz and Nepal. With the exceptions of Indonesia, Kyrgyz and Nepal, these countries are less poor than the first group and rely less heavily on OOP financing. The low mean OOP budget shares in Indonesia and Nepal, despite their heavy reliance on OOP financing, indicate low aggregate levels of spending on health care. This reflects the severity of poverty and the prioritisation of subsistence needs. In the two high-income territories operating a social insurance model with co-payments - Korea and Taiwan - the mean OOP budget share is in the middle of the range, around $3.8 \%$. The lower average budget share in Hong Kong $(2.3 \%)$ is understandable given its higher levels of income and population health and, in comparison with Korea, its lower reliance on OOP financing.

Within each territory, there is a great deal of variation in the OOP budget share across households, suggesting that OOP payments are highly unpredictable. With the exceptions of India, Kyrgyz, Taiwan and Vietnam, the standard deviation of the share is at least 1.9 times the mean. This coefficient of variation is greatest in the four countries with the smallest mean shares - Malaysia, Thailand, Indonesia and the Philippines. The distributions are all highly right-skewed with the mean twice the median or more in all cases but for Taiwan, China and Vietnam. Using the median as measure of central tendency, Taiwan is among the territories with the highest OOP budget shares. This, together with the relatively limited variance and skewness in Taiwan, is explained by high rates of utilisation (O'Donnell et al., 2005), extensive co-payments for most services but high insurance coverage of inpatient care. It is less clear why the distribution is relatively dense in Vietnam. A possible explanation is that the extensive practice of self-medication gives rise to consistently high OOP payments (Chang and Trivedi 2003).

With the exceptions of China and Taiwan, concentration indices of OOP budget shares are positive, indicating that the better-off spend a larger fraction of their resources on health care. This can also be observed in the quintile specific means of the OOP budget share. The gradient is steepest in Bangladesh, the Philippines, Indonesia and India. In Bangladesh, the richest fifth of households, on average, spend almost $9 \%$ of the household budget on health care, while the poorest fifth spend less than $3 \%$. Bangladesh, India and Indonesia are among the poorest countries included in the study. The most plausible explanation of the steep income gradients in these countries is that the better-off can respond to health problems with the purchase of medical care and medicines, while the poorest of the poor cannot afford to divert resources from other pressing demands on very constrained budgets. However, one should not overlook the fact that the poorest households in Bangladesh - a very poor country spend a larger fraction of their available resources on health care than the richest households in highincome Hong Kong. This is explained by the tremendous differences in population health and insurance coverage. China and Vietnam are similar to Bangladesh and India in having a high mean OOP budget share but differ in that the distribution does not display a steep income gradient. In China, the rich actually spend relatively less out-of-pocket on health care. A consequence, one might suppose, of the lack of any fee exemptions for the poor, the collapse of collective payment schemes in rural areas and the greater health insurance cover enjoyed by the better-off, urban population (Henderson et al., 1995; Bloom and Gu, 1997; Carrin et al., 1997; Akin et al., 2004). Fee waivers exist in Vietnam but, at the time of the survey, were restricted to the indigent identified by village committees (Table II). Hong Kong appears to shield the poor better from charges than the social insurance systems of Korea and Taiwan.

Our finding that the OOP budget share is most often increasing with the household budget is inconsistent with the common assertion that the poor spend proportionately more out-of-pocket on health care in low-income countries (Whitehead et al., 2001). The evidence cited to support this 


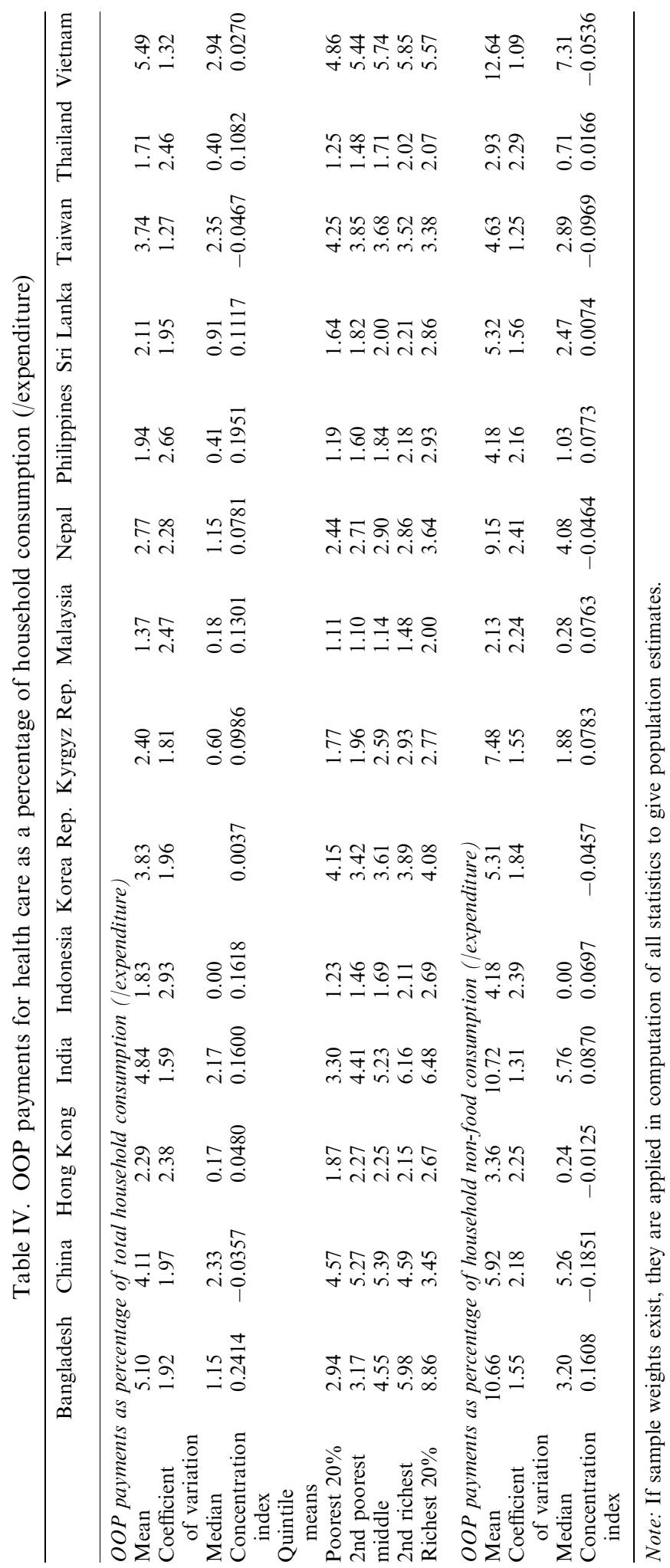


assertion is not from nationally representative expenditure surveys but from health surveys conducted in one, usually rural, region (Ensor and Pham, 1996; Pannarunothai and Mills, 1997; Fabricant et al., 1999; Segall et al., 2002). ${ }^{2}$ Such surveys ignore payments made by the better-off urban population and do not measure total household resources as accurately as expenditure surveys, often relying on income, which, particularly for poor households, is less indicative of living standards in developing countries than is consumption. Support for our finding that the OOP budget share typically increases with total household consumption is provided by a study of India that is based on nationally representative expenditure survey data (Peters et al., 2001).

The relationship between the OOP budget share and the size of the budget will be biased in a positive direction, however, if health care is financed from savings, credit or the sale of assets rather than from the sacrifice of current consumption. In that case, the total expenditure of households spending heavily on health care will be temporarily raised above permanent income. They appear better-off than they actually are.

Besides the endogeneity of total consumption, the tendency for the OOP budget share to rise with the size of the household budget may reflect the fact that poor households devote the larger part of available resources to covering subsistence expenses on food and shelter. The disruptive effect of OOP payments on the living standards of the poor might be better assessed through their share of household resources net of non-discretionary expenses. Definition of the latter is obviously problematic. Non-food expenditures are an approximation (Wagstaff and Van Doorslaer, 2003). The mean share of OOP payments in household non-food expenditures is presented in the bottom part of Table III. The differences between the OOP shares of total and of non-food expenditures are greater in the poorer countries, reflecting the greater share of resources devoted to food. The OOP share remains highest in Bangladesh, India and Vietnam, with 10.6-12.6\% of non-food expenditures spent on health care. In Kyrgyz and Nepal, both of which are very poor, the ratio of OOP payments to total expenditure is relatively moderate but the OOP share of non-food expenditure is very high. The relative position of China moves in the opposite direction, reflecting its higher level of income. The switch in denominator results in a consistent fall in the value of concentration indices. This is to be expected given that the item removed from the denominator - food - is a necessity. Six of the indices are now negative, indicating that the OOP share of non-food expenditure falls as the level of non-food expenditure rises. This relationship is particularly strong in China.

\section{CATASTROPHIC PAYMENTS}

Reliance on OOP financing leaves households exposed to the risk of incurring high medical expenses should a household member fall ill. If the health care expenses were large relative to household resources, the disruption to material living standards could be substantial and may be considered catastrophic. Ideally, longitudinal data would be used to estimate the extent to which living standards are seriously disrupted by the purchase of medical care in response to illness shocks. This would allow one to identify how spending on non-medical goods and services changes following some health shock (Gertler and Gruber, 2002). But appropriate panel data are not available for all countries included in this study. An approximation to the disruptive effect of health expenditures on material living standards must be made. We follow a number of authors in defining medical spending as 'catastrophic' if it exceeds some fraction of total household resources (Berki, 1986; Wyszewianski, 1986; Wagstaff and Van Doorslaer, 2003; Xu et al., 2003; Russell, 2004). The idea is that spending a large fraction of the household budget on health care must be at the expense of consumption of other goods and services. This opportunity cost may be incurred in the short term, if health care is financed by cutting back on

\footnotetext{
${ }^{2}$ See also unpublished reports cited by (Fabricant et al., 1999), that are also usually specific to one rural region.
} 
current consumption, or in the long-term, if it is financed through savings, the sale of assets or credit. ${ }^{3}$ The welfare loss from the sacrifice of current consumption will be greater. But long-term consequences could also be severe. For example, if depleted savings or assets are not sufficient to meet subsequent economic shocks, or if the household sinks into a spiral of debt. The health payments budget share alone does not tell us what financing strategy has been adopted and therefore does not allow distinction between short and long term effects.

Approximating the catastrophic economic consequences of illness through high health payments budget shares has a number of limitations. First, it identifies only the households that incur catastrophic medical expenditures and ignores those that cannot meet these expenses and so forgo treatment. Through the subsequent deterioration of health, such households probably suffer a greater loss of welfare than those incurring catastrophic payments. Recognising this, Pradhan and Prescott (2002) attempt to estimate exposure to, rather than incurrence of, catastrophic payments. Second, there is no distinction between types of medical care purchased. A wealthy household with the capacity to spend a large fraction of its budget on cosmetic surgery would not usually be considered to have experienced a catastrophe, but it would be considered catastrophic for a poor household to spend the same fraction on essential medicines for a sick child. However, in low-income settings in particular, little medical care consumption would be considered frivolous. Below, we present estimates of catastrophic payments that differentially weight large health budget shares incurred by the rich and the poor. Third, the choice of the threshold budget share above which health payments are considered catastrophic is obviously subjective. A common choice has been $10 \%$ of total expenditure (Pradhan and Prescott, 2002; Ranson, 2002; Wagstaff and Van Doorslaer, 2003); with the rationale that this represents an approximate threshold at which the household is forced to sacrifice other basic needs, sell productive assets, incur debt, or be impoverished (Russell, 2004). Here we consider a range of thresholds defined with respect to both total consumption and non-food consumption. As argued above, use of the latter might be more appropriate to assess the disruptive effect of OOP payments on the living standards of the poor. ${ }^{4}$ Notwithstanding these limitations, most households that spend a substantial fraction of their budget on health care can be expected to experience a disruption to their material living standards. Such spending may therefore be used as a proxy to part of the catastrophic economic consequences of illness.

In Table $\mathrm{V}$, we present the catastrophic payment headcount $\left(H_{\mathrm{C}}\right)$ - the percentage of households incurring catastrophic payments (Wagstaff and Van Doorslaer, 2003). Let $T_{i}$ be OOP payments of household $i, x_{i}$ be household consumption (total or non-food), $z$ be the threshold budget share and $E_{i}$ be an indicator equal to 1 if $T_{i} / x_{i}>z$ and zero otherwise. Then, $H_{c}=\left(\sum_{i-1}^{n} E_{i} / n\right) \times 100$, where $n$ is the sample size. The headcount necessarily falls as the threshold is raised. For example, $28 \%$ of Bangladeshi households spend in excess of $5 \%$ of the total household budget on health care and a substantial $4.5 \%$ spend in excess of a quarter of the budget on health care. ${ }^{5}$ Changing the threshold does not affect substantially the countries that have the highest/lowest incidence of catastrophic payments (Figure 1). Catastrophic payments are most prevalent in Bangladesh,

\footnotetext{
${ }^{3}$ For evidence on strategies households adopt to finance medical expenditures see (Ensor and Pham, 1996; Sauerbron et al., 1996; Wilkes et al., 1998; Peters et al., 2001; Skarbinski et al., 2002; van Damme, 2004; Bonu et al., 2005).

${ }^{4}$ Researchers at the World Health Organisation ( $\mathrm{Xu}$ et al., 2003) set the threshold at $40 \%$ of capacity to pay, defined as nonsubsistence effective income. This is household expenditure net of the estimated cost of subsistence food needs. Subsistence spending on food is defined as the average food expenditure of households in the 45th-50th percentile of the food budget share distribution. Since the food budget share is declining with the total budget, this will roughly correspond to the food expenditure of those with median welfare (taking food share a money metric indicator of utility). Actual food expenditure is used for those spending less than this value. We prefer to avoid the problem of estimating subsistence food needs and keep the analysis more transparent by referring to OOP as a share of total and of non-food expenditure.

${ }^{5}$ We have computed standard errors for all point estimates but do not give them in the tables. With large samples, the simple parameters of interest are estimated with a high degree of precision. Presentation of standard errors would clutter the tables to little advantage.
} 


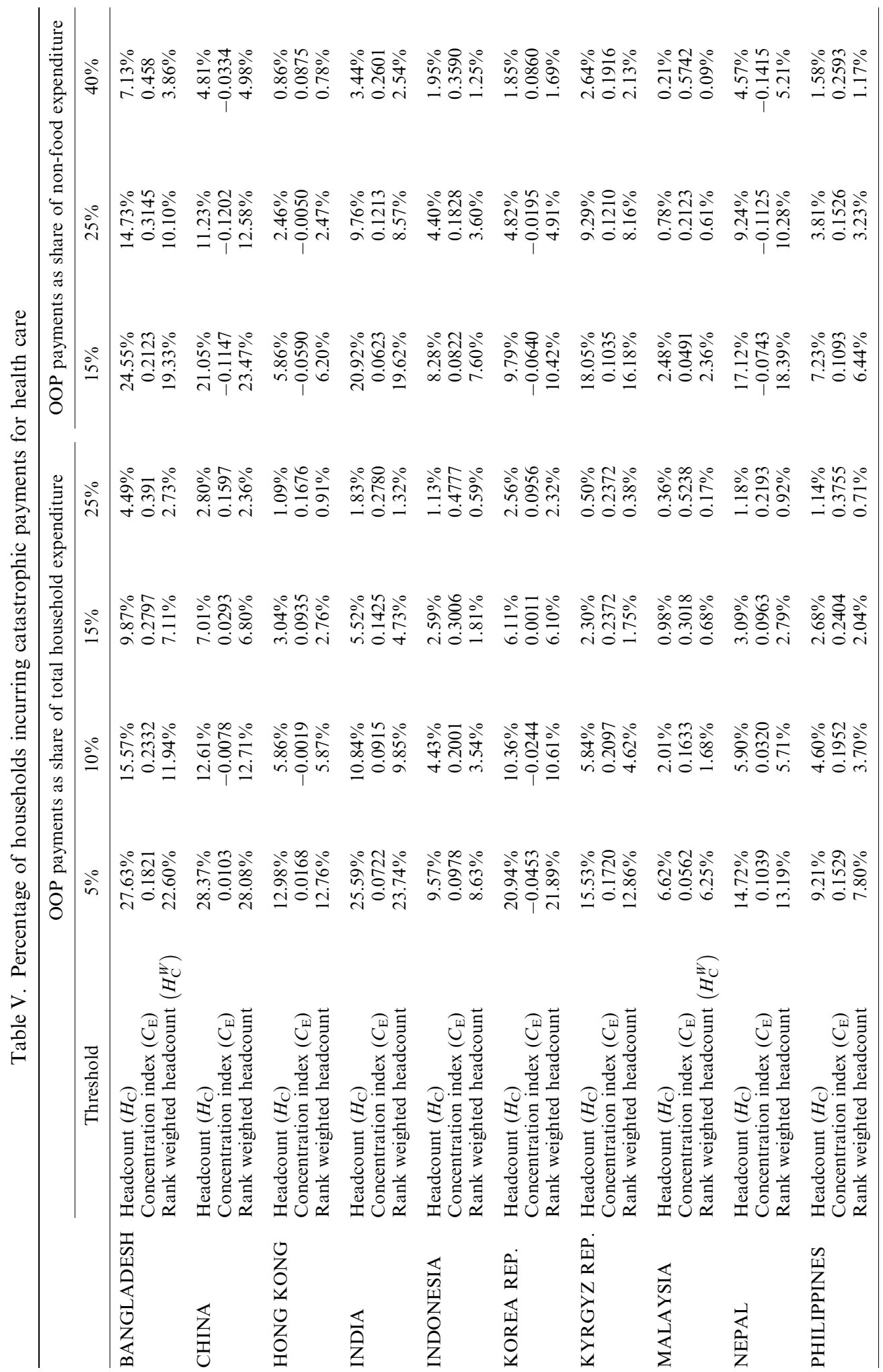




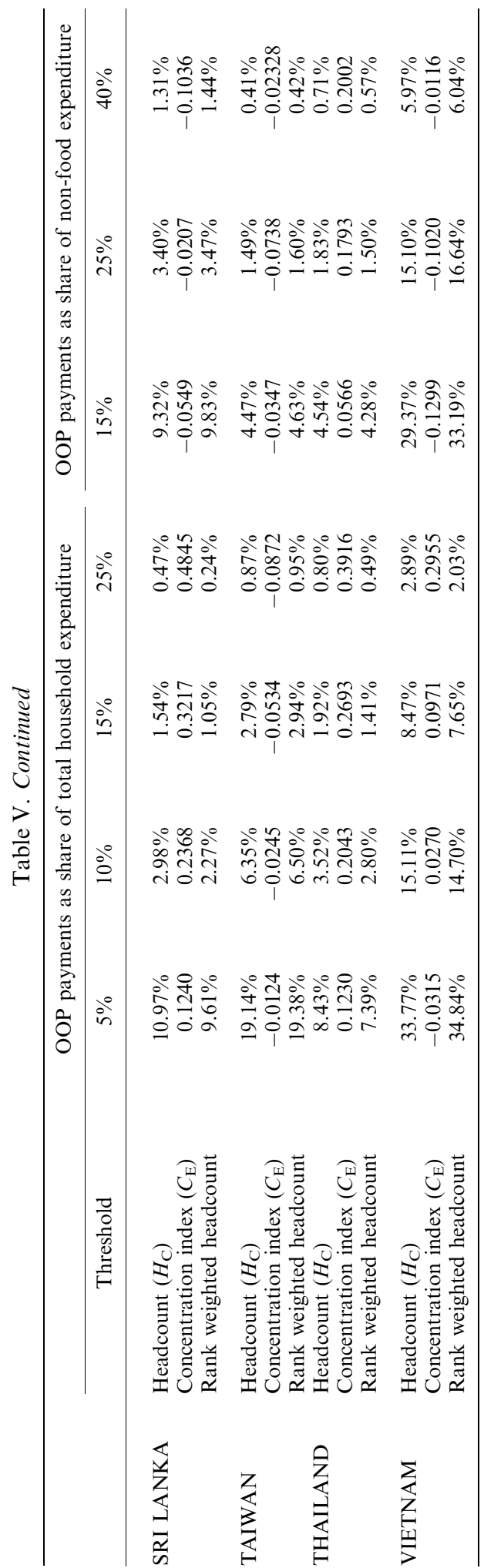




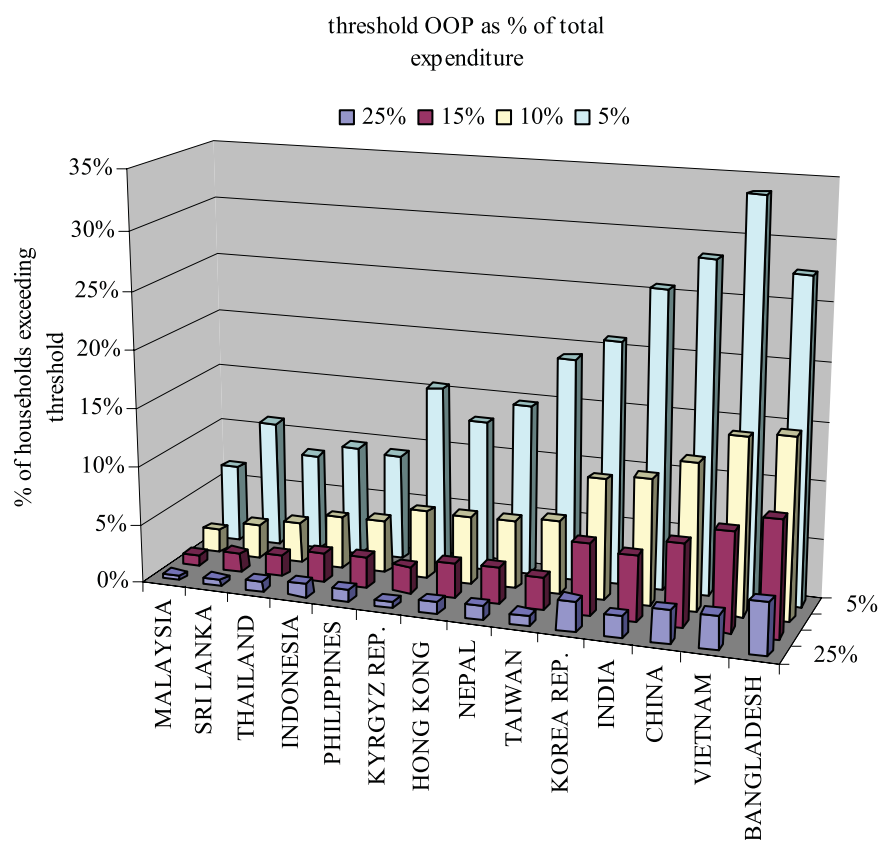

Figure 1. Percentage of households incurring catastrophic payments - various thresholds for OOP as $\%$ of total expenditure

Vietnam, China and India. Vietnam has a higher proportion of households than Bangladesh spending in excess of $5 \%$ of the budget on health care but the ordering is reversed at all higher threshold values. At the lower threshold value of $5 \%$, Korea is close to Taiwan, with around $20 \%$ of households spending in excess of this threshold. But at higher thresholds, Korea is closer to the high incidence group and actually has a higher proportion of households than India, spending in excess of $15 \%$ and even $25 \%$ of the budget. In fact, direct payments for health care absorb in excess of $25 \%$ of total expenditure in a remarkable $2.5 \%$ of Korean households. This reflects the very extensive use of co-payments, the non-coverage of many treatments and, in particular, the partial coverage of expensive inpatient care provided by the Korean social insurance system. By contrast, in Taiwan protection against very high OOP expenditures is similar to that in tax-financed Hong Kong. The incidence of catastrophic payments is lowest in Malaysia, Sri Lanka, Thailand, Indonesia and the Philippines, with less than $5 \%$ of households spending more than $10 \%$ of total expenditures on health care.

Table $\mathrm{V}$ also provides the catastrophic payments headcount defined at 15, 25 and $40 \%$ of non-food expenditures. Bangladesh, China, India and Vietnam continue to have the highest incidence of catastrophic payments. Comparing the headcounts defined at $25 \%$ of non-food expenditure with those at $10 \%$ of total expenditure, which are broadly similar in magnitude on average, we see that there are some significant re-rankings of the other countries (Figure 2). In particular, Kyrgyz and Nepal now join the other low-income countries in having a high proportion of households spending in excess of $25 \%$ of non-food expenditure. The degree of poverty in Kyrgyz and Nepal means that food absorbs a very large share of the household budget and the share of total resources that can be devoted to health care is limited. Once basic food needs have been met, health care accounts for a large fraction of the remaining resources for a substantial fraction of the population. The high-income territories shift down the ranking. Korea is no longer amongst the countries with the highest incidence and Taiwan now has the 


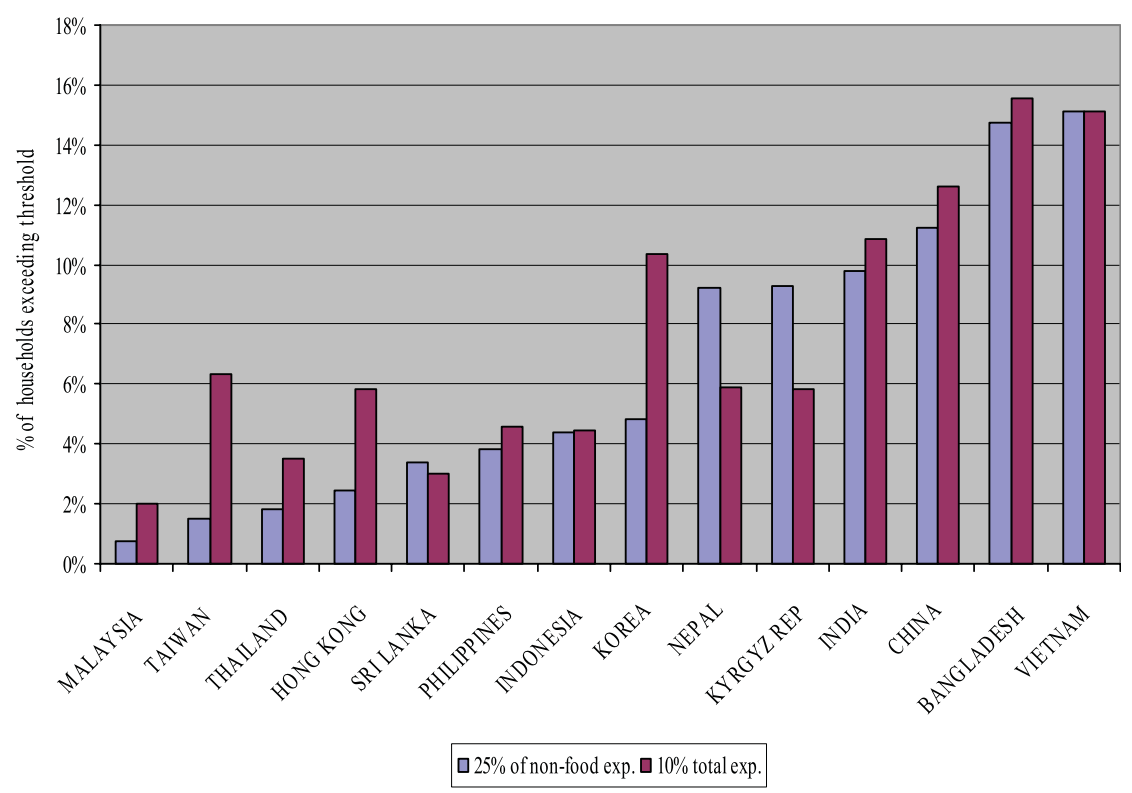

Figure 2. Incidence of catastrophic payments defined relative to total and to non-food expenditures

second lowest incidence. The grouping of territories by prevalence remains constant irrespective of the threshold of non-food expenditure share used. ${ }^{6}$

The incidence of catastrophic payments should be higher where health spending is larger as a share of national income and there is greater reliance on OOP financing of health care. It will also be increasing with the variance and the density of the right-hand tail of the OOP payments distribution. Figure 3 confirms, as has been demonstrated previously ( $\mathrm{Xu}$ et al., 2003), that countries relying most on OOP financing generally have the greatest incidence of catastrophic payments. Of course, reliance on OOP financing is negatively correlated with national income and so there is a negative relationship between the incidence of catastrophic payments and national income. India and Nepal appear to have a lower incidence, given their level of reliance on OOP financing, than Bangladesh and Vietnam. In part, this is due to differences in the magnitude of health spending. The mean health payments budget share is lower in Nepal than in both Vietnam and Bangladesh and is lower in India than in Vietnam (Table V). The incidence is lower in India than in Bangladesh not because mean spending is lower but because the OOP budget share distribution displays less variance and right skewness (Table V). While China relies on OOP financing only slightly more than Indonesia, the prevalence of catastrophic payments is much higher in China than Indonesia. This is due to the greater propensity to spend on medicine in China (Table V). There is also some evidence that social protection is effective in reducing exposure to catastrophic health payment risks in Indonesia (Pradhan and Prescott, 2002).

\footnotetext{
${ }^{6}$ There are some apparent inconsistencies between our estimates of the catastrophic payment headcount at $40 \%$ of non-food expenditure and those of $\mathrm{Xu}$ et al. (2003) at $40 \%$ of capacity to pay. The respective figures are as follows, with the Xu et al estimates in parentheses: Bangladesh $-7.13 \%(1.21 \%)$; Indonesia $-1.95 \%(1.26 \%)$; South Korea $-1.85 \%(1.73 \%)$; Kyrgyz $2.64 \%(0.62 \%)$; Philippines - 1.58\% (0.78\%); Sri Lanka - 1.31\% (1.25\%); Thailand - 0.71\% $(0.80 \%)$; Vietnam - 5.97\% $(10.45 \%)$. Since Xu et al define capacity to pay as the smaller of estimated subsistence food needs and actual food expenditure, our estimates should always be greater than theirs. Clearly this does not hold for Vietnam and, to a lesser extent, Thailand. Our estimates of the headcount are, in a relative sense, much higher for Bangladesh and the Philippines.
} 


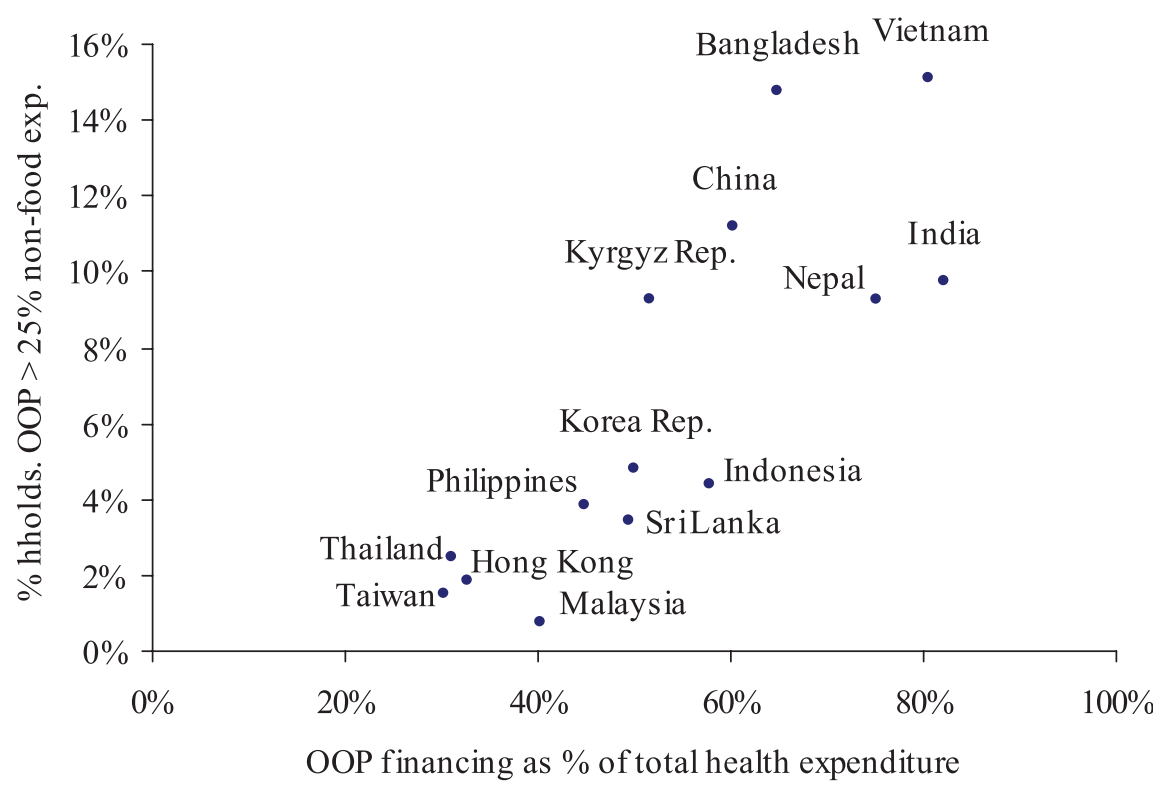

Figure 3. Catastrophic headcount against OOP financing share (OOP $>25 \%$ of non-food exp)

The correlation of catastrophic payments indicator $\left(E_{i}\right)$ with household rank in the distribution of living standards is reflected in the concentration indices $\left(C_{E}\right)$ presented in Table V (Wagstaff and Van Doorslaer, 2003). A positive index means incidence is rising with household living standards. Using total consumption as the measure of living standards and the reference for catastrophic payments, incidence is generally increasing with living standards. The better-off are more likely to spend large fractions of total consumption on health care. The strength of the correlation increases as the threshold is raised. This is consistent with health care being a luxury good, although we should be careful in placing an income elasticity interpretation on a bivariate relationship. Switching to non-food consumption gives smaller concentration indices that are more often negative. This is to be expected given food expenditures are a larger share of the budget of poorer households.

There is cross-country variation in the correlation between the incidence of catastrophic payments and living standards that seems to be attributable to differences in national income, financing structure and user charging policy. Figure 4 shows the concentration indices for the catastrophic headcount defined at $10 \%$ of total consumption. In the higher-income countries, there is either no correlation or the poor are more likely to incur catastrophic payments. Only in Taiwan are the poor more likely to spend in excess of $15 \%$ of total expenditure on health care (Table V). Catastrophic payments are made disproportionately by the better-off in Malaysia, Philippines, Indonesia, Thailand, Kyrgyz, Bangladesh and Sri Lanka. In each of these countries, with the exception of Kyrgyz and to a lesser extent Malaysia, the poor are exempted from public sector user charges where they exist (Table II). This is not the case in China and Vietnam, where there is a high incidence of catastrophic payments that the poor are no less likely to incur.

If one wishes to place a normative interpretation on catastrophic payments, then it may be considered appropriate to give more weight to excess payments incurred by poorer households. Large expenditures on health care that are incurred by better-off households at the cost of expendable consumption may be judged quite differently from payments made by poor households that are forced to cut back on consumption of basic necessities. A statistic that reflects not only the incidence but also the distribution of catastrophic payments is computed by multiplying the catastrophic headcount by the complement of 


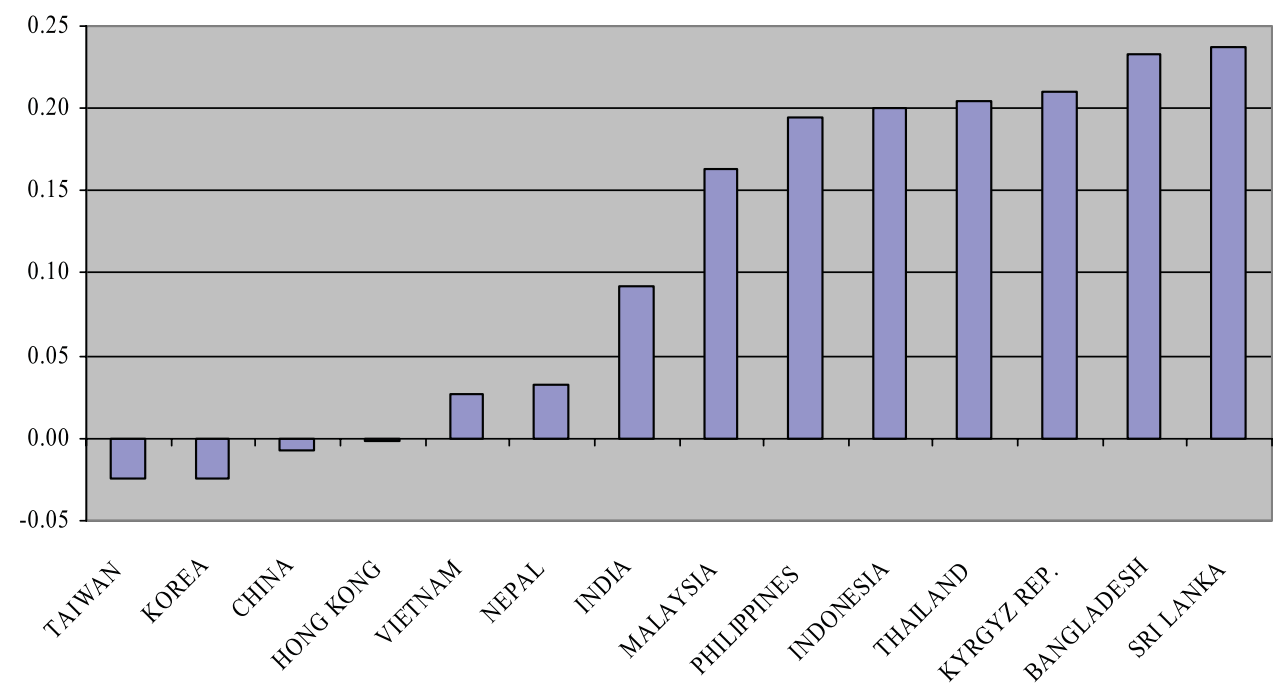

Figure 4. Concentration indices for catastrophic headcount (OOP $>10 \%$ total exp)

its concentration index, $H_{\mathrm{C}}^{W}=H_{\mathrm{C}} \cdot\left(1-C_{E}\right)$ (Wagstaff and Van Doorslaer, 2003). This statistic is equivalent to a weighted sum of a catastrophic payment indicator variable, $E_{i}$, with weights declining linearly from 2 to 0 as one moves from the worst-off to the best-off household. ${ }^{7}$ If households exceeding the threshold tend to be better-off, the concentration index $C_{E}$ will be positive, and $H_{\mathrm{C}}^{W}$ will be less than $H_{\mathrm{C}}$. This is generally the case, with the opposite arising consistently only in Taiwan and, occasionally, depending on the threshold, in China, South Korea and Vietnam (Table V). But the difference between the weighted and unweighted indices is generally modest (Figure 5). Taking account of the distribution has relatively little impact on the cross-country picture. Given the high concentration of catastrophic payments on the better-off in Bangladesh, its weighted incidence moves down relative to that of China and Vietnam.

The headcount gives the incidence and not the intensity of catastrophic payments. Intensity may be measured by the payment in excess of the threshold averaged over all households exceeding the threshold - the mean positive overshoot (MPO) (Wagstaff and Van Doorslaer, 2003). Define a household's excess payment, or threshold overshoot, by $O_{i}=E_{i}\left(\left(T_{i} / x_{i}\right)-z\right)$. Then, MPO $=\sum_{i=1}^{n} O_{i} /$ $\sum_{i=1}^{n} E_{i}$. Both the prevalence and intensity of catastrophic payments are reflected in the mean catastrophic payment overshoot $(O)$ - payments in excess of the threshold average over all households. We can write $O=H_{c} \times \mathrm{MPO}$, making clear that the mean overshoot is increasing with both the incidence and the intensity of catastrophic payments.

Since the majority do not incur catastrophic payments, the mean overshoot $(\mathrm{O})$ is dominated by the incidence. It is not surprising, therefore, that the overshoot statistics presented in Figure 6 display the same general pattern across countries as the headcount statistics (see also Table VI). There are, however, a few notable exceptions. Defining catastrophic payments at $25 \%$ of non-food expenditure, Nepal has the highest mean overshoot (Figure 6), although it had only the fifth highest incidence (Figure 2), implying a very high intensity of catastrophic payments. Amongst those spending more than

\footnotetext{
${ }^{7}$ Such weighting obviously introduces normative judgements with respect to relative societal tolerance of catastrophic payments incurred at different points in the income distribution. This is inevitable in any attempt to summarise both the level and the distribution of some variable in one statistic. Without wishing to claim that the specific weighting scheme adopted reflects a social consensus, we suggest that the majority would wish to place more weight on catastrophic payments incurred by poorer households.
} 


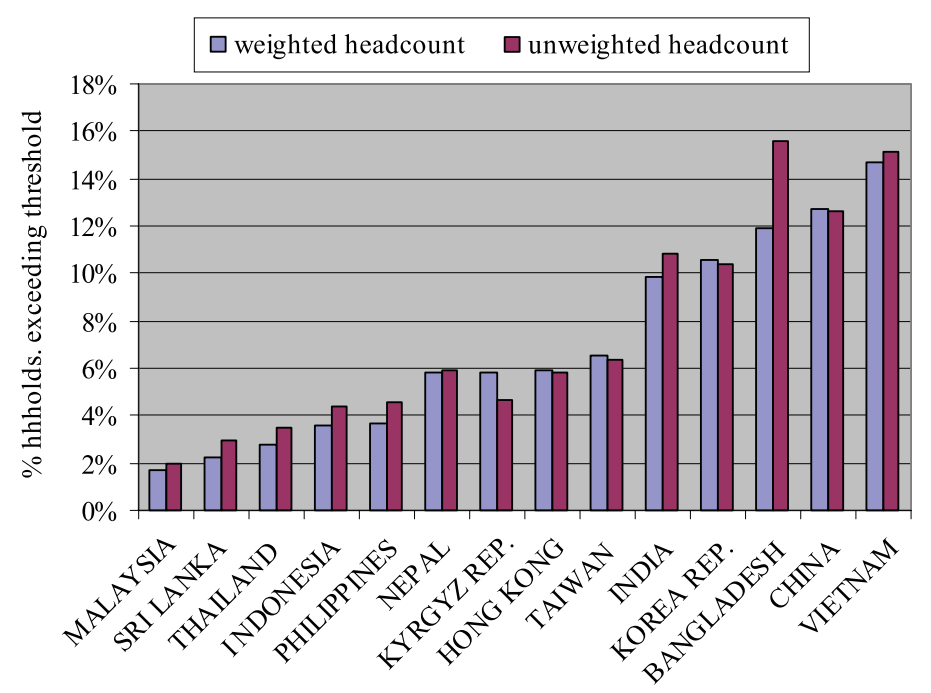

Figure 5. Distribution weighted and unweighted incidence of catastrophic payments (OOP $>10 \%$ total exp)

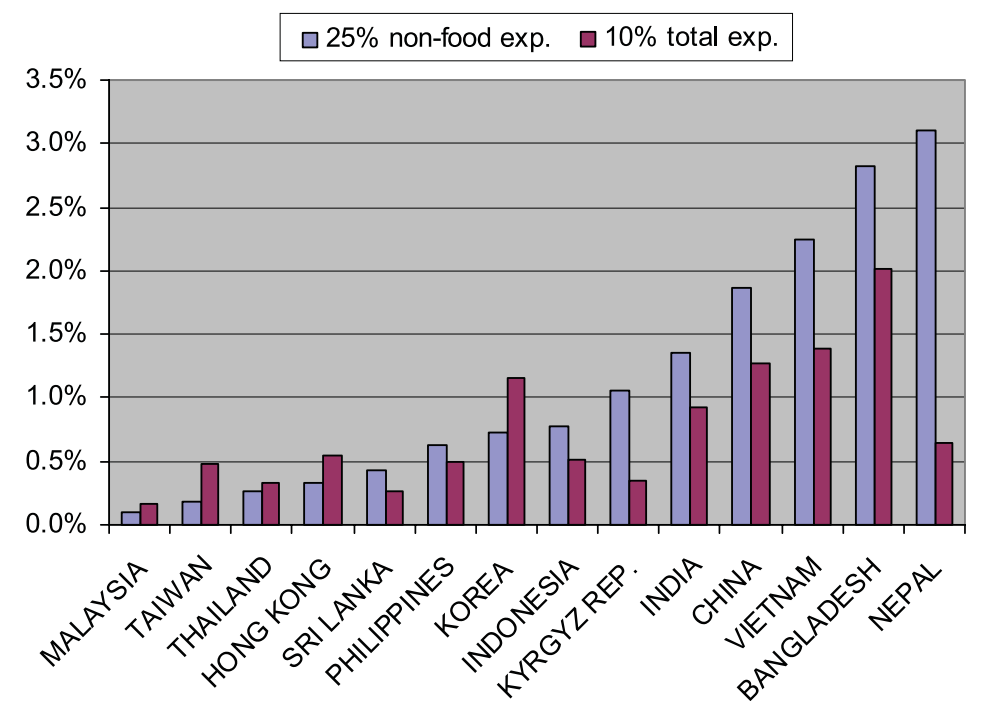

Figure 6. Mean catastrophic overshoot

$25 \%$ of total non-food expenditure on OOP payments in Nepal, the average OOP share exceeds this threshold by 34 percentage points (Table VI), giving a staggering 59\% OOP budget share. In Bangladesh, the average budget share for those exceeding the $25 \%$ of non-food expenditure threshold is $44 \%$ and among the equivalent 'overshooters' in Taiwan, it is $37 \%$. But only $1.5 \%$ of households exceed the threshold in Taiwan, compared with almost $15 \%$ in Bangladesh. The much lower cross-country variability in the intensity of catastrophic payments than in the prevalence reflects the fact that, given other needs, there is an upper limit on the proportion of household resources that can be devoted to medical expenditures. Concentration indices for 'excess' health payments generally display similar patterns to the corresponding indices for the incidence. 
Table VI. OOP health payments in excess of catastrophic payments threshold budget share

\begin{tabular}{|c|c|c|c|c|c|c|c|c|}
\hline & \multirow[b]{2}{*}{ Threshold } & \multicolumn{4}{|c|}{$\begin{array}{c}\text { Share of total } \\
\text { consumption/expenditure }\end{array}$} & \multicolumn{3}{|c|}{$\begin{array}{l}\text { Share of non-food } \\
\text { consumption/expenditure }\end{array}$} \\
\hline & & $5 \%$ & $10 \%$ & $15 \%$ & $25 \%$ & $15 \%$ & $25 \%$ & $40 \%$ \\
\hline \multirow[t]{4}{*}{ BANGLADESH } & Mean overshoot $(O)$ & $3.04 \%$ & $2.02 \%$ & $1.40 \%$ & $0.72 \%$ & $4.74 \%$ & $2.83 \%$ & $1.26 \%$ \\
\hline & Concentration index $\left(C_{O}\right)$ & 0.3299 & 0.3915 & 0.4528 & 0.567 & 0.3844 & 0.4667 & 0.592 \\
\hline & Rank weighted overshoot $\left(O^{W}\right)$ & $2.04 \%$ & $1.23 \%$ & $0.76 \%$ & $0.31 \%$ & $2.92 \%$ & $1.51 \%$ & $0.51 \%$ \\
\hline & Mean positive overshoot (MPO) & $11.01 \%$ & $12.98 \%$ & $14.15 \%$ & $16.07 \%$ & $19.32 \%$ & $19.22 \%$ & $17.70 \%$ \\
\hline \multirow[t]{4}{*}{ CHINA } & Mean overshoot $(O)$ & $2.22 \%$ & $1.28 \%$ & $0.81 \%$ & $0.35 \%$ & $3.39 \%$ & $1.86 \%$ & $0.73 \%$ \\
\hline & Concentration index $\left(C_{O}\right)$ & 0.0639 & 0.1056 & 0.1631 & 0.2594 & -0.0697 & -0.0265 & 0.0653 \\
\hline & Rank weighted overshoot $\left(O^{W}\right)$ & $2.08 \%$ & $1.14 \%$ & $0.68 \%$ & $0.26 \%$ & $3.62 \%$ & $1.91 \%$ & $0.69 \%$ \\
\hline & Mean positive overshoot (MPO) & $7.84 \%$ & $10.12 \%$ & $11.52 \%$ & $12.38 \%$ & $16.09 \%$ & $16.57 \%$ & $15.24 \%$ \\
\hline \multirow[t]{4}{*}{ HONG KONG } & Mean overshoot $(O)$ & $0.98 \%$ & $0.55 \%$ & $0.34 \%$ & $0.13 \%$ & $0.73 \%$ & $0.34 \%$ & $0.11 \%$ \\
\hline & Concentration index $\left(C_{O}\right)$ & 0.0854 & 0.1410 & 0.2052 & 0.3140 & 0.0237 & 0.0762 & 0.1719 \\
\hline & Rank weighted overshoot $\left(O^{W}\right)$ & $0.90 \%$ & $0.47 \%$ & $0.27 \%$ & $0.09 \%$ & $0.71 \%$ & $0.31 \%$ & $0.09 \%$ \\
\hline & Mean positive overshoot (MPO) & $7.56 \%$ & $9.40 \%$ & $11.08 \%$ & $12.06 \%$ & $12.40 \%$ & $13.66 \%$ & $12.76 \%$ \\
\hline \multirow[t]{4}{*}{ INDIA } & Mean overshoot $(O)$ & $1.77 \%$ & $0.92 \%$ & $0.53 \%$ & $0.20 \%$ & $2.80 \%$ & $1.35 \%$ & $0.45 \%$ \\
\hline & Concentration index $\left(C_{O}\right)$ & 0.1449 & 0.2080 & 0.2788 & 0.4144 & 0.1609 & 0.2451 & 0.3915 \\
\hline & Rank weighted overshoot (WO) & $1.51 \%$ & $0.73 \%$ & $0.38 \%$ & 0.1 & $2.35 \%$ & $1.02 \%$ & $0.27 \%$ \\
\hline & Mean positive overshoot (MPO) & $6.91 \%$ & $8.49 \%$ & $9.65 \%$ & $11.03 \%$ & $13.39 \%$ & $13.83 \%$ & $12.96 \%$ \\
\hline \multirow[t]{4}{*}{ INDONESIA } & Mean overshoot $(O)$ & $0.83 \%$ & $0.51 \%$ & $0.34 \%$ & $0.17 \%$ & $1.38 \%$ & $0.77 \%$ & $0.32 \%$ \\
\hline & Concentration index $\left(C_{O}\right)$ & 0.3125 & 0.4208 & 0.5069 & 0.6367 & 0.2688 & 0.3770 & 0.5391 \\
\hline & Rank weighted overshoot $\left(O^{W}\right)$ & $0.57 \%$ & $0.29 \%$ & $0.17 \%$ & 0.0 & $1.01 \%$ & 0.4 & $0.15 \%$ \\
\hline & Mean positive overshoot (MPO) & $8.71 \%$ & $11.48 \%$ & $13.09 \%$ & $14.64 \%$ & $16.68 \%$ & $17.62 \%$ & $16.64 \%$ \\
\hline \multirow[t]{4}{*}{ KOREA } & Mean overshoot $(O)$ & $1.90 \%$ & $1.16 \%$ & $0.76 \%$ & $0.36 \%$ & $1.42 \%$ & $0.73 \%$ & $0.27 \%$ \\
\hline & Concentration index $\left(C_{O}\right)$ & 0.0325 & 0.0778 & 0.1263 & 0.2302 & 0.0233 & 0.0916 & 0.2073 \\
\hline & Rank weighted overshoot $\left(O^{W}\right)$ & $1.84 \%$ & $1.07 \%$ & $0.67 \%$ & 0.2 & $1.39 \%$ & 0.6 & $0.22 \%$ \\
\hline & Mean positive overshoot (MPO) & $9.07 \%$ & $11.23 \%$ & $12.48 \%$ & $13.94 \%$ & $14.52 \%$ & $15.20 \%$ & $14.82 \%$ \\
\hline \multirow[t]{4}{*}{ KYRGYZ REP. } & Mean overshoot $(O)$ & $0.84 \%$ & $0.35 \%$ & $0.15 \%$ & $0.04 \%$ & $2.38 \%$ & $1.06 \%$ & $0.28 \%$ \\
\hline & Concentration index $\left(C_{O}\right)$ & 0.1224 & 0.1938 & 0.2039 & 0.2830 & 0.0851 & 0.1120 & 0.1192 \\
\hline & Rank weighted overshoot $\left(O^{w}\right)$ & $0.74 \%$ & $0.28 \%$ & $0.12 \%$ & $\%$ & $2.18 \%$ & $0.94 \%$ & $0.25 \%$ \\
\hline & Mean positive overshoot (MPO) & $5.44 \%$ & $6.02 \%$ & $6.71 \%$ & $7.46 \%$ & $13.19 \%$ & & $10.70 \%$ \\
\hline \multirow[t]{4}{*}{ MALAYSIA } & Mean overshoot $(O)$ & $0.36 \%$ & $0.17 \%$ & $0.10 \%$ & $0.05 \%$ & $0.24 \%$ & $0.10 \%$ & $0.03 \%$ \\
\hline & Concentration index $\left(C_{O}\right)$ & 0.2542 & 0.4204 & 0.5370 & 0.7232 & 0.2641 & 0.4730 & 0.7388 \\
\hline & Rank weighted overshoot ( & $\%$ & $0.10 \%$ & $0.05 \%$ & 0.0 & $0.18 \%$ & $\%$ & $0.01 \%$ \\
\hline & Mean positive overshoot (MPO) & $5.39 \%$ & $8.58 \%$ & & & $9.62 \%$ & & \\
\hline \multirow[t]{4}{*}{ NEPAL } & Mean overshoot $(O)$ & $1.11 \%$ & $0.64 \%$ & $0.43 \%$ & $0.24 \%$ & $4.35 \%$ & $3.11 \%$ & $2.15 \%$ \\
\hline & Concentration index $\left(C_{O}\right)$ & 0.0579 & 0.0474 & 0.0475 & -0.0418 & -0.2368 & -0.2949 & -0.3695 \\
\hline & Rank weighted overshoot $\left(O^{W}\right)$ & 1 & 0.6 & $0.41 \%$ & & $5.38 \%$ & $4 .($ & \\
\hline & Mean positive overshoot (MPO) & $7.54 \%$ & $10.85 \%$ & & $20.59 \%$ & $25.42 \%$ & $33.66 \%$ & $47.15 \%$ \\
\hline \multirow[t]{4}{*}{ PHILIPPINES } & Mean overshoot $(O)$ & $0.82 \%$ & $0.50 \%$ & $0.32 \%$ & $0.14 \%$ & $1.15 \%$ & $0.62 \%$ & $0.24 \%$ \\
\hline & Concentration index $\left(C_{O}\right)$ & 0.2766 & 0.3427 & 0.4089 & 0.5429 & 0.2055 & 0.2674 & 0.3819 \\
\hline & Rank weighted overshoot ( & $0.60 \%$ & $0.33 \%$ & $0.19 \%$ & $0.07 \%$ & $0.91 \%$ & & \\
\hline & Mean positive overshoot (MPO) & $8.94 \%$ & $10.81 \%$ & $12.01 \%$ & $12.68 \%$ & $15.89 \%$ & $16.36 \%$ & $15.36 \%$ \\
\hline \multirow[t]{4}{*}{ SRI LANKA } & Mean overshoot $(O)$ & $0.56 \%$ & $0.27 \%$ & $0.16 \%$ & $0.07 \%$ & $0.97 \%$ & $0.42 \%$ & $0.15 \%$ \\
\hline & Concentration index $\left(C_{O}\right)$ & 0.2969 & 0.4412 & 0.5553 & 0.7575 & 0.1064 & 0.2376 & 0.4258 \\
\hline & Rank weighted overshoot $\left(O^{W}\right)$ & $0.39 \%$ & $0.15 \%$ & $0.07 \%$ & & $0.87 \%$ & & \\
\hline & Mean positive overshoot (MPO) & $5.09 \%$ & $8.89 \%$ & $10.41 \%$ & $15.56 \%$ & $10.74 \%$ & $13.70 \%$ & $15.05 \%$ \\
\hline \multirow[t]{4}{*}{ TAIWAN } & Mean overshoot $(O)$ & $1.03 \%$ & $0.47 \%$ & $0.26 \%$ & $0.10 \%$ & $0.45 \%$ & $0.18 \%$ & $0.06 \%$ \\
\hline & Concentration index $\left(C_{O}\right)$ & -0.0293 & -0.0457 & -0.0528 & -0.0421 & -0.0442 & -0.0430 & -0.0088 \\
\hline & Rank weighted overshoot $\left(O^{W}\right)$ & $1.06 \%$ & $0.50 \%$ & $0.28 \%$ & & $0.47 \%$ & & \\
\hline & Mean positive overshoot (MPO) & $5.40 \%$ & $7.46 \%$ & $9.39 \%$ & $11.79 \%$ & $9.97 \%$ & $12.07 \%$ & $14.04 \%$ \\
\hline \multirow[t]{2}{*}{ THAILAND } & Mean overshoot $(O)$ & $0.61 \%$ & $0.33 \%$ & $0.20 \%$ & $0.07 \%$ & $0.55 \%$ & $0.26 \%$ & $0.08 \%$ \\
\hline & Concentration index $\left(C_{O}\right)$ & 0.2474 & 0.3337 & 0.3907 & 0.5349 & 0.1508 & 0.1970 & 0.2172 \\
\hline
\end{tabular}


Table VI. Continued

\begin{tabular}{|c|c|c|c|c|c|c|c|c|}
\hline & \multirow[b]{2}{*}{ Threshold } & \multicolumn{4}{|c|}{$\begin{array}{c}\text { Share of total } \\
\text { consumption/expenditure }\end{array}$} & \multicolumn{3}{|c|}{$\begin{array}{l}\text { Share of non-food } \\
\text { consumption/expenditure }\end{array}$} \\
\hline & & $5 \%$ & $10 \%$ & $15 \%$ & $25 \%$ & $15 \%$ & $25 \%$ & $40 \%$ \\
\hline & Rank weighted overshoot $\left(O^{W}\right)$ & $0.02 \%$ & $0.01 \%$ & $0.01 \%$ & $0.00 \%$ & $0.47 \%$ & $0.21 \%$ & $0.06 \%$ \\
\hline & Mean positive overshoot (MPO) & $7.25 \%$ & $9.39 \%$ & $10.41 \%$ & $9.05 \%$ & $12.22 \%$ & $14.22 \%$ & $11.13 \%$ \\
\hline \multirow[t]{4}{*}{ VIETNAM } & Mean overshoot $(O)$ & $2.53 \%$ & $1.39 \%$ & $0.81 \%$ & $0.30 \%$ & $4.35 \%$ & $2.24 \%$ & $0.76 \%$ \\
\hline & Concentration index $\left(C_{O}\right)$ & 0.0960 & 0.1845 & 0.2821 & 0.4594 & -0.0681 & -0.0197 & 0.0809 \\
\hline & Rank weighted overshoot $\left(O^{W}\right)$ & $2.28 \%$ & $1.13 \%$ & $0.58 \%$ & $0.16 \%$ & $4.65 \%$ & $2.28 \%$ & $0.69 \%$ \\
\hline & Mean positive overshoot (MPO) & $7.48 \%$ & $9.18 \%$ & $9.58 \%$ & $10.46 \%$ & $14.81 \%$ & $14.83 \%$ & $12.66 \%$ \\
\hline
\end{tabular}

Notes: Definitions of mean overshoot and mean positive overshoot provided in text. Concentration index is for the household level overshoot, $O_{i}$. Rank weighted overshoot is equal to $O \times\left(1-C_{O}\right)$.

\section{CONCLUSION}

There is still heavy reliance on out-of-pocket financing of health care in Asia. The OOP share of health funding is at least a third in all territories included in this study, exceeds three-fifths in Bangladesh and China and over three quarters in Vietnam, India and Nepal. This paper has substantially increased the comparative evidence on the magnitude, the distribution and the economic consequences of OOP payments for health care in Asia. It will facilitate more informed discussion of health care financing across the continent. The main findings are as follows. First, heavy reliance on OOP financing appears to have important consequences for household living standards. For example, OOP payments for health care absorb more than one quarter of household resources net of food costs in at least $10 \%$ of all households in Bangladesh, China, India, Nepal and Vietnam. Such levels of spending can only be accommodated through the diversion of considerable resources from current consumption and/or through the accumulation of debt or the exhaustion of savings and assets with long-term consequences for household welfare. Second, there are important differences across countries in the incidence of catastrophic health payments. It is generally higher in low-income countries that rely more on OOP financing and lower in high/middle-income countries that make greater use of prepayment mechanisms. But there is also substantial variation at similar levels of national income. Third, the distribution of catastrophic payments also differs across countries. In high-income countries, they tend to be evenly distributed, or even slightly concentrated on the less well-off. In most low-income countries, however, it is households with higher total expenditure that are more likely to spend a large fraction of those resources on health care. This may reflect the inability of the poorest of the poor to divert resources from other basic needs and possibly the protection of the poor from user charges offered in some countries. But in China, Kyrgyz and Vietnam, where there were no exemptions of the poor from charges at the time of the surveys analysed, the poor were as likely, or even more likely, to incur catastrophic payments.

It is not surprising that catastrophic payments are generally more pervasive in low-income countries financing health care principally by direct payments and less pervasive in high-income countries with more developed prepayment methods of finance. But the analysis reveals interesting differences within each of these two groups. Malaysia, the Philippines, Sri Lanka and Thailand have managed to contain the OOP health financing share below that found in most low and middle income countries and all have a relatively low incidence of catastrophic payments. Bangladesh, China, India, Nepal and Vietnam stand out in relying heavily on OOP financing and having a high incidence of catastrophic payments. While the second group of countries is, in general, poorer, there is little difference between the average incomes of China and Sri Lanka. The latter is striking as a low-income country that manages to rely on OOP payments for just less than half of health financing and still further because the catastrophic impact of these payments are modest. This reflects the near absence of charges in the public sector. The majority of OOP payments are made by 
the better-off for private alternatives to public care. Indonesia relies on OOP financing only slightly less than China but has much smaller catastrophic impact of health payments. In part, this may be due to targeted exemptions in Indonesia, implemented through a health card, that have had some success in shielding poor families from high health payments (Pradhan and Prescott, 2002). The lack of such a scheme in China not only results in a greater prevalence of catastrophic payments but also in a greater concentration of OOP payments on low-income households. But the low incidence of catastrophic payments in Indonesia also reflects the low propensity to spend on health care. ${ }^{8}$ Thailand has been even more successful than Sri Lanka in constraining the living standards consequences of OOP health payments. Its more developed economy with a larger formal sector allows a greater share of health funding to be raised from taxes. In addition, an effective health card system has protected the poor from charges and the introduction of universal coverage, with a flat rate minimal charge, has further weakened the impact of OOP payments on household budgets. In Malaysia, charges for public sector care have been kept low and catastrophic payments largely avoided. Among the three high-income territories, the incidence of catastrophic payments is much higher in Korea than in Hong Kong and Taiwan due to the substantial co-payments within the Korean social insurance system and, particularly, the partial coverage of inpatient care.

While this study significantly expands the available evidence on the living standards consequences of OOP payments for health care in Asia, it provides only a partial picture of a multifaceted problem. Besides the occurrence of catastrophic payments, lack of insurance against health care expenses imposes other costs on household welfare that should be examined in complementary analyses. First, households may be impoverished by health payments. We have addressed this issue for the low/middle income countries included in the study elsewhere (Van Doorslaer et al., 2006). Second, OOP payments raise the price barrier to the quantity and quality of care consumed. As noted above, poor households may not be observed to incur catastrophic payments since they cannot afford to divert spending from subsistence food needs. The flip side of catastrophic payments is the catastrophic loss of health and subsequent erosion of earnings capacity due to inability to afford health care. It is therefore important to complement the study of health care payments with that of health care utilization (O'Donnell $\mathrm{O}$ et al., 2007). In addition to medical spending, illness shocks have catastrophic economic consequences through lost earnings. In fact, Gertler and Gruber (2002) find earnings losses to have a more disrupting effect on household living standards than medical spending following a health shock in Indonesia. The lack of sickness and disability insurance may impose an even greater welfare loss than that of health care insurance.

\section{ACKNOWLEDGEMENTS}

We are grateful to two anonymous referees and to participants at seminars of the Global Health Institute at Harvard University and in Santiago de Chile for helpful comments on an earlier version. The European Commission, INCO-DEV programme (ICA4-CT-2001-10015), funded the EQUITAP project from which this paper derives. Analysis for Taiwan was funded by Taiwan Department of Health (DOH91-PL-1001 and DOH92-PL-1001) and for Hong Kong by the Health, Welfare and Food Bureau, Government of the Hong Kong Special Administrative Region.

\section{APPENDIX A}

The description of surveys is given in Table AI.

\footnotetext{
${ }^{8}$ In 2000 , total expenditure on health was only $2.7 \%$ of GDP in Indonesia, compared, for example, with $5.3 \%$ in China (World Health Report, 2002).
} 


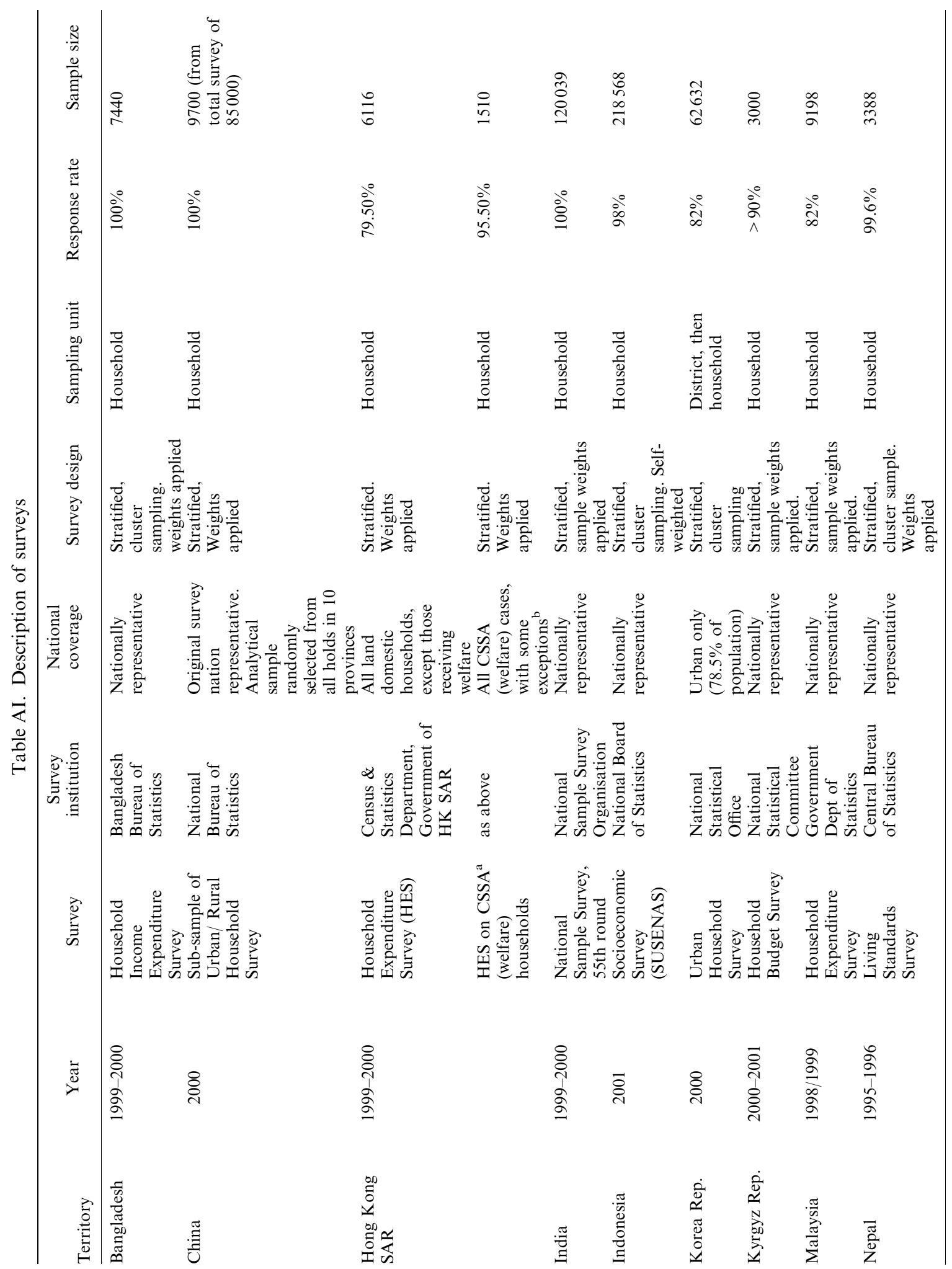




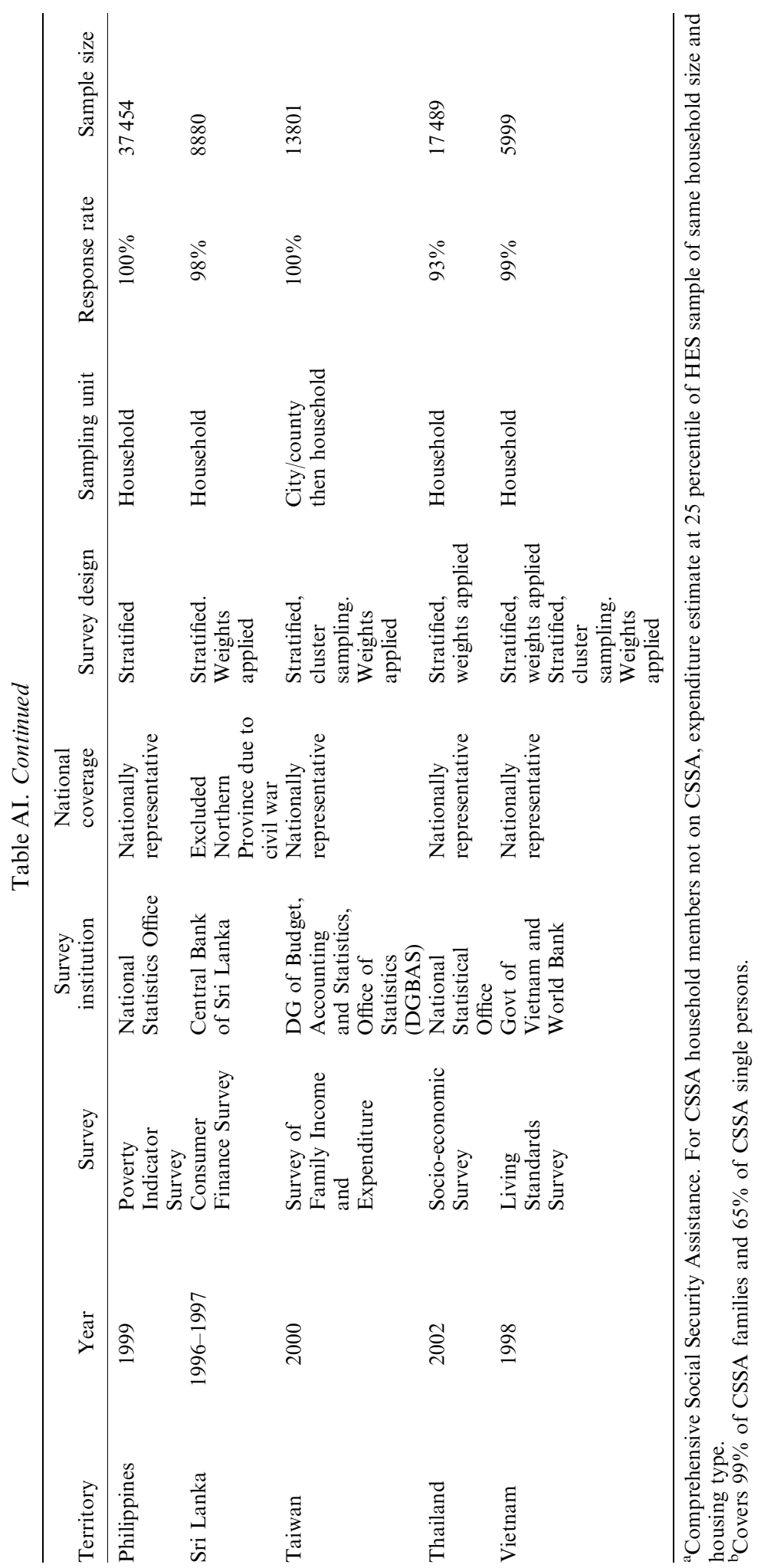




\section{REFERENCES}

Akin J, Dow WH, Lance PM. 2004. Did the distribution of health insurance in China continue to grow less equitable in the nineties? Results from a longitudinal survey. Social Science \& Medicine 58: 293-304.

Berki SE. 1986. A look at catastrophic medical expenses and the poor. Health Affairs 5(4): 138-145.

Bloom G, Gu X. 1997. Health sector reform: Lessons from China. Social Science \& Medicine 45(3): 351-360.

Bonu S, Rani M, Peters DH, Jha R et al. 2005. Does use of tobacco or alcohol contribute to impoverishment from hospitalization costs in India? Health Polcy and Planning 20(1): 41-49.

Carrin G, Aviva R, Yang H et al. 1997. The reform of the rural cooperative medical system in the People's Republic of China: Interim experience in 14 pilot counties. Social Science \& Medicine 48(7): 961-972.

Chang F-R, Trivedi PK. 2003. Economics of self-medication: Theory and evidence. Health Economics 12(9): 721-739.

Commission on Macroeconomics and Health. 2001. Macroeonomics and Health: Investing in Health for Economic Development. World Health Orgnanisation: Geneva.

Data International Ltd. 2004. Bangladesh National Health Accounts, 1999-2001. Health Economics Unit, Ministry of Health and Family Welfare: Dhaka.

Deaton A. 2004. Measuring Poverty in a Growing World (or Measuring Growth in a Poor World). Princeton University, Princeton, NJ.

Ensor T, Pham BS. 1996. Access and payment for health care: The poor of nothern Vietnam. International Journal of Health Planning and Management 11: 69-83.

Fabricant SJ, Kamara CW, Mills A. 1999. Why the poor pay more: Household curative expenditures in rural Sierra Leone. International Journal of Health Planning and Management 14: 179-199.

Gertler P, Gruber J. 2002. Insuring consumption against illness. American Economic Review 92(1): 51-70.

Henderson G, Jin S, Akin J, Li Z et al. 1995. The distribution of medical insurance in China. Social Science \& Medicine 41(8): 1119-1130.

Hotchkiss DR, Rous JJ, Karmacharya K, Sangraula P. 1998. Household health expenditures in Nepal: Implications for health care financing reform. Health Policy and Planning 13(4): 371-383.

Khoman S. 1997. Rural health care financing in Thailand. In Innovations in health care financing: Proceedings of a World Bank Conference, Scheieber GJ (ed.), 10-11 March. The World Bank: Washington, DC, 183-193.

Mudur G. 1999. Abuse of OTC drugs rising in South Asia. British Medical Journal 318: 556.

O’Donnell O, Van Doorslaer E, Rannan-Eliya R et al. 2005. Who pays for health care in Asia? EQUITAP, Working Paper \# 1. Erasmus University, Rotterdam and IPS, Colombo.

O’Donnell O, van Doorslaer E, Rannan-Eliya RP et al. 2007. The incidence of public spending on health care: comparative evidence from Asia. World Bank Economic Review, in press. doi: 10.1093/wber/lhl009

OECD and WHO. 2003. DAC Guidelines and Reference Series - Poverty and Health. Paris, OECD and WHO: Paris.

Pannarunothai S, Mills A. 1997. The poor pay more: health-related inequality in Thailand. Social Science \& Medicine 44(12): 1781-1790.

Peters D, Yazbeck A, Sharma R et al. 2001. Better Health Systems for India's Poor. Findings, Analysis and Options. World Bank: Washington, DC.

Pradhan M, Prescott N. 2002. Social risk management options for medical care in Indonesia. Health Economics 11: 431-446.

Ranson MK. 2002. Reduction of catastrophic health care expenditures by a community-based health insurance scheme in Gujarat, India: Current experiences and challenges. Bulletin of the World Health Organisation 80(8): 613-621.

Russell S. 2004. The economic burden of illness for households in developing countries: a review of studies focusing on malaria, tuberculosis, and human immunodeficiency virus/acquired immunodeficiency syndrome. American Journal of Tropical Medicine and Hygiene 71(Suppl. 2): 147-155.

Saadah F, Pradhan M, Sparrow R. 2001. The Effectiveness of the Health Card as an Instrument to Ensure Access to Medical Care for the Poor During the Crisis. World Bank: Washington, DC.

Sauerbron R, Adams A, Hien M. 1996. Household strategies to cope with the economic cost of illness. Social Science \& Medicine 43(3): 291-301.

Sauerbron R, Ibrangho I, Nougtara A et al. 1995. The economic costs of illness for rural households in Burkina Faso. Tropical Medicine \& Parasitol 42: 219.

Segall M, Tipping G, Lucas H et al. 2002. Economic transition should come with a health warning: the case of Vietnam. Journal of Epidemiology and Community Health 56: 497-505.

Skarbinski J, Walker HK, Baker L et al. 2002. The burden of out-of-pocket payments for health care in Tblisi, Republic of Georgia. Journal of American Medical Association 287(8): 1043-1049.

van Damme W. 2004. Out-of-pocket health expenditure and debt in poor households: evidence from Cambodia. Tropical Medicine and International Health 9(2): 273-280. 
Van Doorslaer E, O'Donnell O, Rannan-Eliya RP et al. 2006. Effect of health payments on poverty estimates in 11 countries in Asia: An analysis of household survey data. The Lancet 368(14): 1357-1364.

Wagstaff A, Van Doorslaer E. 2003. Catastrophe and impoverishment in paying for health care: with applications to Vietnam 1993-98. Health Economics 12: 921-934.

Whitehead M, Dahgren G, Evans T. 2001. Equity and health sector reforms: can low-income countries escape the medical poverty trap? The Lancet 358: 833-836.

Wilkes AHY, Bloom G, Xingyuan G. 1998. Coping with the costs of severe illness in rural China. IDS Working Paper 58, Brighton, Sussex, UK.

World Bank. 2001. Growing Healthy? A Review of Vietnam's Health Sector. The World Bank: Hanoi.

World Bank. 2004. The Millenium Development Goals for Health: Rising to the Challenges. World Bank: Washington, DC.

World Health Organisation. 2000. World Health Report 2000. World Health Organisation: Geneva.

World Health Organisation. 2005. Sustainable health financing, universal coverage and social health insurance. 115th World Health Assembly Resolution EB115.R13, Geneva.

Wyszewianski L. 1986. Financially catastrophic and high cost cases: Definitions, distinctions and their implications for policy formulation. Inquiry 23(4): 382-394.

Xu K, Evans DE, Kawabate K et al. 2003. Household catastrophic health expenditure: a multicountry analysis. Lancet 362: 111-117. 